\title{
The Reciprocal Relationships Among Parents' Expectations, Adolescents' Expectations, and Adolescents' Achievement: A Two-Wave Longitudinal Analysis of the NELS Data
}

\author{
Yanyan Zhang • Eileen Haddad • Bernadeth Torres • \\ Chuansheng Chen
}

Received: 28 March 2010/ Accepted: 29 June 2010/Published online: 14 July 2010

(c) The Author(s) 2010. This article is published with open access at Springerlink.com

\begin{abstract}
Previous research has consistently demonstrated the importance of parents' expectations and adolescents' expectations on adolescents' academic achievement. Less is known, however, about the reciprocal relationships among these constructs. To address this issue, we analyzed two waves of data from the National Education Longitudinal Study of 1988 (NELS:88) using longitudinal cross-lagged path models. The sample consisted of 14,376 students (51.1\% females; $6.5 \%$ Asian, $11.1 \%$ Hispanic, $9.2 \%$ African American, and $73.2 \%$ White). Results indicated that there was a reciprocal relationship between parents' expectations and adolescents' expectations (i.e., they had mutual influence on each other). Moreover, there was a reciprocal relationship between expectations (both parents' and adolescents') and adolescents' academic achievement. Multiple-group analyses of gender and ethnicity revealed that the effects of parents' expectations on students' expectations were stronger among males than among females. With respect to ethnic differences, the effects of adolescents' expectations were weakest on parents' expectations among African Americans as compared to the other ethnic groups (i.e., Asian, Hispanic and White). Implications of these findings are discussed.
\end{abstract}

Keywords Parental expectations - Adolescents' expectations - Adolescents' achievement . Gender differences · Ethnic differences

Y. Zhang $(\varangle) \cdot$ E. Haddad $\cdot$ B. Torres $\cdot$ C. Chen Department of Psychology and Social Behavior, University of California at Irvine, 4201 Social \& Behavioral Sciences Gateway, Irvine, CA 92697-7085, USA e-mail: yanyan.zhang@uci.edu

\section{Introduction}

Because of their important effects on academic achievement, adolescents' academic expectations have been widely studied within the field of adolescent development (Wigfield and Eccles 2002). To conceptualize the formation of adolescents' academic expectations, particularly the impact of previous academic achievement and the social context on adolescents' academic expectations, Wigfield and Eccles (2002) developed the expectancy-value theory of achievement motivation. The theory states that the individual's expectations and values are influenced by their social context (parents, teachers, peers, neighborhood, and community) and previous academic achievement. Once established, an individual's expectations and values then influence the individual's academic performance, persistence, and academic subject choice (Eccles and Wigfield 2002). In other words, the theory posits causal relationships from social context (e.g., parental expectations) to students' own expectations and to their academic achievement.

Lending support to the expectancy-value theory, much literature has demonstrated the importance of parental academic expectations in shaping their children's academic expectations (e.g., Bandura et al. 1996; Goyette and Xie 1999; Smith 1981). For example, Bandura et al. (1996) found that children whose parents had high academic aspirations for them generally had higher academic selfefficacy compared to children whose parents did not. Smith (1981) found that both perceived maternal and paternal academic expectations were significantly associated with adolescents' own expectations, and that the association was stronger for mothers' academic expectations than for those of the fathers. Parental academic expectations were also positively associated with adolescents' academic expectations in a sample of immigrant youths (Aldous 2006). 
Thus, parents' expectations clearly influence the formation of adolescents' academic expectations.

In addition to influencing adolescents' academic expectations, parents' expectations can also influence adolescents' academic achievement. For example, Aldous (2006) found that adolescents' academic achievement was high when parents and adolescents both had high academic expectations. Furthermore, a recent study by Benner and Mistry (2007) explicitly tested the mechanisms by which parents' and teachers' educational expectations affect adolescents' academic achievement. Their findings suggested that parents' and teachers' expectations independently influenced youth's academic outcomes, and that high parental expectations buffered the negative effects of low teacher expectations. Perceptions of parental expectations (rather than actual expectations) can also positively influence adolescents' academic achievement. It is important to note, however, that discrepancies between students' expectations and their perceptions of their parents' expectations can lead to negative achievement outcomes. To illustrate, in their study of an ethnically diverse sample, Hao and Bonstead-Bruns (1998) found that adolescents who perceived that their parents had similar expectations as they did tended to perform well academically. On the other hand, when there was a perceived mismatch in students' and parents' expectations, the students' academic performance suffered. Taken together, these studies indicate the important influence parental expectations, and perceived parental expectations, can have on adolescents' academic achievement.

Expectancy-value theory is useful in explaining not only how parents' expectations influence adolescents' expectations and achievement, but also how parents' expectations are developed (Wigfield and Eccles 2002). In fact, several recent studies have suggested that the relationship between parents' expectations and adolescents' achievement is reciprocal in nature. For example, in an analysis involving longitudinal path models, Mistry et al. (2009) found that parents' expectations and teachers' expectations are dynamic and responsive to adolescents' achievement and performance across time. A similar study by Goldenberg et al. (2001) examined the reciprocal relationship between parental expectations and students' school performance in a sample of Latino families (Goldenberg et al. 2001). Findings from the study indicated that students' school performance influenced parents' expectations, but contrary to other studies (e.g., Benner and Mistry 2007; Goyette and Xie 1999), parental expectations did not influence students' performance. In sum, there is much empirical evidence to suggest that not only do parents' expectations influence students' expectations and achievement, but also that students' achievement can influence parents' expectations. Little to no research, however, has examined whether adolescents' expectations can influence parents' expectations. Furthermore, although expectancy-value theory suggests that, in addition to prior levels of students' academic achievement, cultural stereotypes (which may include traditional gender roles and/or racial or ethnic stereotypes) can influence parents' expectations (Wigfield and Eccles 2002), the empirical evidence for this notion remains unclear.

\section{Gender Differences in Academic Expectations}

Studies have demonstrated the presence of gender differences in math and verbal abilities, as well as gender differences in occupational attainment (Halpern 2000). To understand these differences, previous literature has looked to the possibility of gender differences in expectations. Findings of such studies, however, have been inconsistent; some observed significant gender differences, whereas others found no apparent gender differences. For example, Mau and Bikos (2000) found that females tended to have higher mean educational and occupational expectations than males. Morgan (1996) found that both White and African American females demonstrated higher expectations than did males from the same ethnic groups. Recently, Mello and Swanson (2007) also found similar gender differences in a sample of urban African American adolescents.

Males and females also differ in the extent to which their expectations were affected by those of their parents. Rosen and Aneshensel (1978) noted that, although both males' and females' educational expectations were influenced by perceived parental expectations, the effects of parental expectations were greater between mothers and daughters than between fathers and sons. A related and more recent study found that, although mothers' educational expectations influenced their daughters' future locus of control, this relationship did not replicate among males (Flouri and Hawkes 2008), further suggesting that females are more sensitive to their parents' expectations than males.

In contrast to these findings, other researchers have found males and females to be quite similar with respect to academic expectations (e.g., Ensminger and Slusarick 1992; Garg et al. 2002; Mello 2008; Rosen and Aneshensel 1978; Trusty 1998). For example, in a sample of lowincome African American students, Ensminger and Slusarick (1992) longitudinally examined males' and females' academic expectations and found that they were similarly associated with their mothers' academic expectations, and this similarity remained from first grade through high school. A study by Mello (2008) found that, although gender differences existed with respect to occupational expectations, males and females had similar academic 
expectations. Additionally, a longitudinal study on adolescents' expectations found no differences between males and females with respect to mean levels of academic expectations (Trusty 1998). Thus, the literature on gender differences and academic expectations remains inconclusive.

\section{Ethnic Differences in Academic Expectations}

Ethnic disparities in academic achievement also have been well-documented by previous research. Asian students typically outperform White students, who in turn typically outperform African-American and Hispanic students (Patton and Royer 2009; NCES 2005a, b). Ethnic differences in students' academic expectations have been identified as an important contributor to the differences in achievement (Aldous 2006). Ethnic variations in parents' academic expectations may also contribute to ethnic differences in academic achievement (Aldous 2006). It is possible that the effects of high parental expectations may be especially beneficial for adolescents from ethnic minority backgrounds, who are vulnerable to educational barriers such as lower socioeconomic status and racial stereotypes. However, although ethnic minority parents (and students) may have higher expectations than Whites, the former has been found to be less stable. For example, Kao and Tienda (1998) found that African American and Hispanic adolescents had less stable academic expectations than White and Asian adolescents. The authors speculated that African American and Hispanic adolescents were more likely to be from lower socioeconomic backgrounds and were less informed about their educational opportunities. Kao and Tienda (1998) added that Hispanic and African American adolescents have initially high educational expectations, but when they realize their educational opportunities are limited (either from low socioeconomic status or poor grades), they are more likely to make downward adjustments to their expectations.

In general, however, research has shown that high parental expectations are beneficial to academic achievement regardless of adolescents' ethnic backgrounds (Aldous 2006; Chen and Lan 1998; Patrikakou 1997; Smith 1981, 1991). In a longitudinal study, Patrikakou (1997) found that across all ethnic groups examined, both perceived and actual parental expectations were influential to adolescents' academic expectations. Similarly, Smith (1981, 1991) found that high parental expectations had beneficial effects on both African American and White adolescents. In assessing the academic achievement of Asian American adolescents, studies have found that Asian American adolescents perceived their parents as having higher academic expectations than other ethnic groups, which may explain their higher academic achievement (e.g., Chen and Lan 1998; Goyette and Xie 1999). Taken together, these studies demonstrate how ethnic differences in students' and parents' expectations can contribute to ethnic differences in achievement.

\section{The Current Study}

Although several studies have examined how the social context influences adolescents' academic expectations, much less is known about how parents' and adolescents' academic expectations influence each other over time, and how these expectations are differentially related to academic achievement across gender and ethnic groups. The current study used cross-lagged longitudinal path models to examine how parents' expectations, adolescents' own expectations, and adolescents' academic achievement influence one another over a four-year period (from 8th grade to 12 th grade), and how these effects may be moderated by gender and ethnicity (see Fig. 1).

In this study, we tested four main hypotheses. First, it was predicted that there would be reciprocal relationships between parents' academic expectations and students' academic expectations. More specifically, we expected that students' expectations in 8th grade would predict changes in parents' expectations from 8th to 12th grade, and parents' expectations in 8th grade would predict changes of students' expectations from 8th to 12th grade.

Second, reciprocal relationships between students' academic achievement and students' and parents' academic expectations were expected. In other words, we predicted that 8th grade expectations held by both students and parents would predict changes in academic achievement from 8th to 12th grade, and that academic achievement in 8th grade would predict changes in students' and parents' expectations from 8th to 12th grade.

Third, we hypothesized that the reciprocal relationships among students' expectations, parents' expectations, and academic achievement would differ by gender. More specifically, in light of previous literature which indicated that females' expectations were more susceptible to influence by parents' expectations than were males' expectations (Flouri and Hawkes 2008), we predicted that parents' expectations would have a stronger effect on females' expectations than on those of males.

Finally, we expected that the reciprocal relationships in the proposed model would differ by ethnicity. Although previous research has generally shown positive effects of parents' expectations on students' achievement (e.g., Aldous 2006; Chen and Lan 1998; Smith 1981, 1991), these studies did not provide direct tests using longitudinal data. Furthermore, none of the studies emphasized the possible effects of previous students' expectations on later 
Fig. 1 Conceptual model of the current study

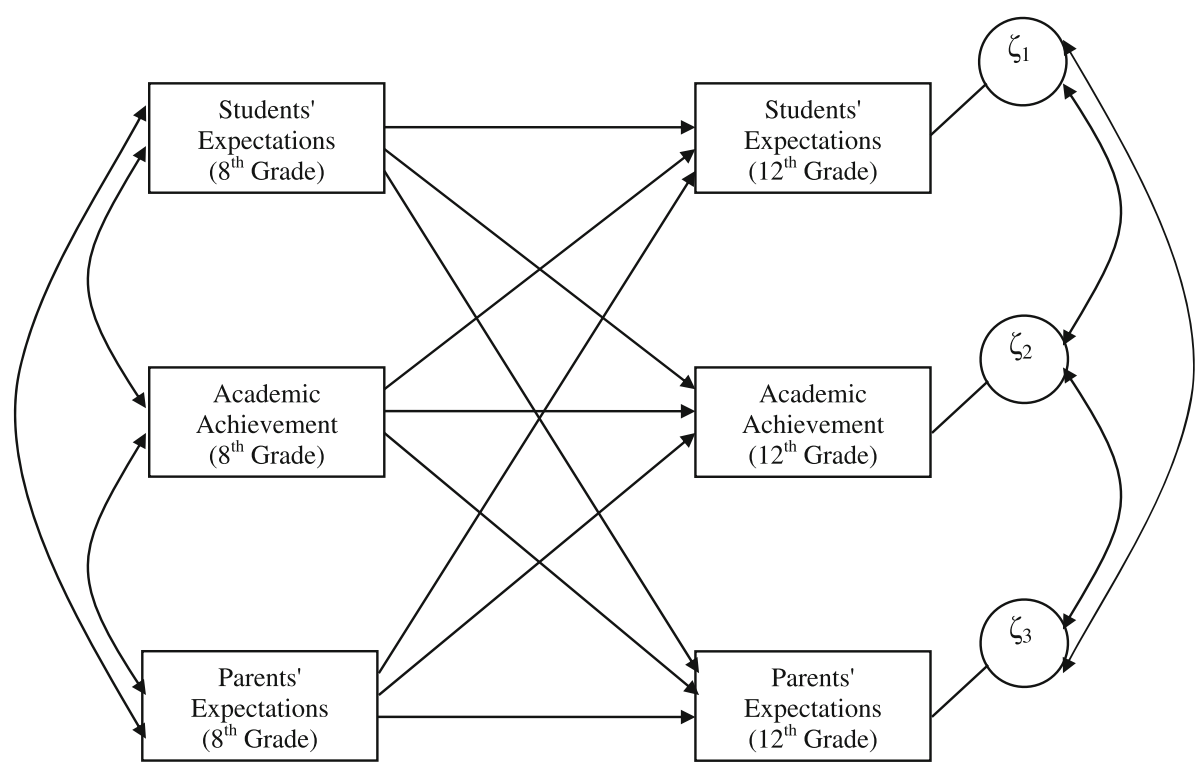

parents' expectations. We predicted that the effects of parents' expectations on students' expectations would be greater for ethnic groups (e.g., Asian Americans) that value familism and academic achievement (Sue and Okazaki 1990) than for other groups. In contrast, we expected that groups that value autonomy and independence (e.g., European Americans vs. Asian Americans, Feldman and Rosenthal 1990; Feldman et al. 1995) would show greater effects of students' expectations on parents' expectations.

\section{Method}

\section{Dataset}

For this study, we used data from the National Education Longitudinal Study of 1988 (NELS:88). NELS:88 is a large-scale longitudinal study that follows a nationally representative sample of 24,599 8th graders beginning in 1988. A subsample of these respondents were then resurveyed in 1990, when most were in 10th grade; in 1992, when most were in 12th grade; and in 1994 and 2000, when most were out of high school for 2 and 8 years, respectively. Data from parents were collected during the 1988 (Base Year) and 1992 (Follow-Up 2) waves of data collection. Thus, this survey provides a rich source of information about students' expectations, parents' expectations and the academic achievement of adolescents for those two waves, which were used in the current study.

The NELS used a two-stage sampling procedure. In the first stage, over 1,000 schools ( 815 public and 237 private) were selected with probabilities proportional to their 8thgrade enrollments. In the second stage, approximately 26 students from each school were randomly sampled on the condition that they did not have serious physical or emotional problems, a mental handicap, or inability to speak the English language. The NELS sampling strategy ensured that gender, socioeconomic, and racial/ethnic characteristics (among other characteristics) of the NELS sample matched census data and were nationally representative (Ingels et al. 1998).

Data collection for NELS included both paper-andpencil surveys and telephone interviews. In 1988, 1990 and 1992, paper-and-pencil surveys were administered to selected students via group sessions, normally conducted in a classroom. The 1994 and 2000 rounds were out-of-school data collection sessions. For these two waves, students had moved onto postsecondary education, dropped out, or moved into the workforce. Due to the geographic dispersion of the subjects, computer-assisted telephone interviews (CATI) were used, as were self-administered surveys and field personnel administered surveys. Estimated response rates varied by collection wave, but remained consistently high at around or above $90 \%$ (see Ingels and Quinn 1996 for additional sampling and response rate information).

\section{Sample}

Of the original 24,599 students, a subsample of 14,376 students were followed from 8th-grade through the spring of 1992, when most were in 12th grade. The reduction in sample size is primarily due to budgetary constraints that prevented the NELS research team from pursuing further follow-up information after the initial 8th grade assessments (for a detailed examination of this issue, see Ingels et al. 1992). The sample is approximately evenly distributed by gender (48.9\% males, $51.1 \%$ females), and 
ethnically diverse $(6.5 \%$ Asian, $11.1 \%$ Hispanic, 9.2\% African American, $73.2 \%$ White).

\section{Measures}

The key variables used in this study included students' academic expectations, parents' academic expectations, and academic achievement, with gender and ethnicity examined as potential moderators.

\section{Students' Academic Expectations}

Students' academic expectations were assessed using the item, "As things stand now, how far in school do you think you will get?" The responses were recoded to reflect five levels: $1=$ "less than high school", $2=$ "high school diploma", 3 = "some college", 4 = "bachelors degree", and $5=$ "beyond bachelors" (meaning, attending graduate or professional school).

\section{Parents' Academic Expectations}

Parents' academic expectations were assessed using the item, "How far in school do you want your teenager to go?" Consistent with the students' expectations scale, the responses for this scale were recoded to reflect five levels of academic expectations: 1 = "less than high school", $2=$ "high school diploma", $3=$ "some college", $4=$ "bachelors degree", and $5=$ "beyond bachelors" (meaning, attending graduate or professional school).

\section{Academic Achievement}

Students' academic achievement was assessed using a composite of students' scores on standardized tests in mathematics and reading, which were administered by the NELS research team (Curtin et al. 2002). Math tests contained items in arithmetic, algebra, geometry, and probability, and advanced topics and were divided into categories of skill and/or knowledge, understanding and/or comprehension, and problem solving. Reading tests consisted of reading passages from one paragraph to one page in length, followed by three to six questions based on each passage. The mean test score was approximately 50 with a standard deviation of about 10 . Because the range of this scale was drastically different from the variables for expectations, we used standardized $Z$ scores in the path analyses to allow for a more intuitive interpretation of the size of the coefficients.

\section{Moderator Variables}

Gender was coded as $0=$ males and $1=$ females, and ethnicity was coded as $1=$ Asians, $2=$ Hispanics,
$3=$ African Americans, and $4=$ Whites. Although the original dataset included American Indians and "Other/ Mixed" as a possible response, the sample sizes for these groups were not sufficient for separate analyses and were thus included only in the total-sample analysis, but not in group-level analysis.

\section{Plan of Analyses}

Cross-lagged path models, which test longitudinal effects while controlling for other variables in the model, were used to examine the relationships among students' academic expectations, parents' academic expectations, and academic achievement. Multiple-group analyses were used to test for gender and ethnic differences in the model. In multiple-group analyses, to test whether differences are present across groups, we constrained each path and calculated a difference in $\chi^{2}$. A significant $\Delta \chi^{2}$ indicates that group differences are present in the model. To test more precisely which paths differed across groups, we unconstrained each path one-by-one to identify the path(s) showing significant group differences. It is worth mentioning that in path models, the path coefficients reflected "unique" or "independent" associations between two variables just as in multiple regressions. Therefore, when we found a significant coefficient from Variable A at Time 1 to Variable B at Time 2, this coefficient reflected Variable A's contribution to Variable B after considering other variables in the model including Variable B at Time 1. In other words, such a coefficient meant Variable A at Time 1 predicted changes in Variable B from Time 1 to Time 2 (with changes conceptualized as regression residuals).

To analyze the NELS data properly, several analytic issues need to be addressed. The NELS utilized complex sampling designs that entailed stratifying the country into geographic regions, creating clusters of schools within each geographic region, and using unequal selection probability of individuals within each cluster to create a nationally representative sample (Ingels et al. 1998). Simple random sampling assumptions are violated in complex sampling designs such as the NELS. In our analyses, we followed the guidelines of using the NELS data and took into consideration necessary adjustments for the clustering, stratification, and weighting of this dataset in order to avoid bias in standard error estimation (Muthén and Satorra 1995).

\section{Results}

Before discussing the results based on the path models, we present findings based on the means of students' academic expectations, parents' academic expectations, and academic achievement. As seen in Table 1, females had 
Table 1 Means and standard deviations of academic expectations and achievement $(N=14,376)$

\begin{tabular}{|c|c|c|c|c|c|c|c|c|c|c|c|c|}
\hline & \multicolumn{6}{|c|}{ 8th Grade } & \multicolumn{6}{|c|}{ 12th Grade } \\
\hline & \multicolumn{2}{|c|}{$\begin{array}{l}\text { Students' } \\
\text { expectations }\end{array}$} & \multicolumn{2}{|c|}{$\begin{array}{l}\text { Parents' } \\
\text { expectations }\end{array}$} & \multicolumn{2}{|c|}{$\begin{array}{l}\text { Academic } \\
\text { achievement }\end{array}$} & \multicolumn{2}{|c|}{$\begin{array}{l}\text { Students' } \\
\text { expectations }\end{array}$} & \multicolumn{2}{|c|}{$\begin{array}{l}\text { Parents' } \\
\text { expectations }\end{array}$} & \multicolumn{2}{|c|}{$\begin{array}{l}\text { Academic } \\
\text { achievement }\end{array}$} \\
\hline & $M$ & SD & $M$ & SD & $M$ & SD & $M$ & SD & $M$ & SD & $M$ & SD \\
\hline \multicolumn{13}{|l|}{ Gender } \\
\hline Male & 3.87 & .90 & 3.80 & .92 & 52.36 & 10.28 & 3.97 & .91 & 4.20 & .83 & 52.04 & 10.00 \\
\hline Female & 3.90 & .87 & 3.83 & .91 & 53.05 & 9.95 & 4.09 & .88 & 4.27 & .78 & 52.59 & 9.40 \\
\hline \multicolumn{13}{|l|}{ Ethnicity } \\
\hline Asians & 4.24 & .83 & 4.24 & .89 & 55.83 & 10.20 & 4.39 & .77 & 4.52 & .67 & 55.97 & 9.60 \\
\hline Hispanics & 3.77 & .98 & 3.67 & 1.01 & 47.54 & 8.68 & 3.92 & .93 & 4.30 & .78 & 48.00 & 8.95 \\
\hline African Americans & 3.92 & .89 & 3.78 & .98 & 46.08 & 8.51 & 4.05 & .89 & 4.37 & .77 & 45.48 & 9.02 \\
\hline Whites & 3.93 & .86 & 3.81 & .88 & 54.11 & 9.88 & 4.01 & .89 & 4.19 & .81 & 53.54 & 9.32 \\
\hline
\end{tabular}

$M$ means, $S D$ standard deviations

slightly higher levels of achievement than males in both 8th and 12th grade $(t(14,374)=-4.015, p<.001$ and $t(14,374)=-3.05, p<.01$, respectively). Females also had higher academic expectations than males in both 8th grade and 12th grade $(t(14,374)=7.89, p<.001$ and $t(14,374)=-7.69, p<.001$, respectively), and parents' expectations where comparable in 8th grade but slightly higher for females than for males in 12th grade $(t(14,374)=-5.00, p<.001)$. With respect to ethnic differences, we found that students' expectations in 8th and 12 th grade were highest among Asians and lowest among Hispanics $(F(3,14,372)=7.53, p<.001$ and $F(3$, $14,372)=13.65, p<.001$, respectively). A similar pattern was observed in parents' expectations, in which parents' expectations in 8th and 12th grade were highest among Asians and lowest among Hispanics $(F(3,14,372)=$ $17.74, p<.001$ and $F(3,14,374)=26.45, p<.001$, respectively). In general, expectations were higher in 12 th grade than in 8th grade, and, in 12th grade, higher among parents than among students.

\section{Overall Model of Reciprocal Relationships}

As shown in Fig. 2, the overall cross-lagged path model demonstrated that students' expectations, parents' expectations, and academic achievement were quite stable across time. Academic achievement was the most stable $(b=.78$, $p<.001$ ), and students' expectations and parents' expectations also demonstrated high stability $(b=.29, p<.001$ and $b=.26, p<.001$, respectively). Of particular relevance to the study, the model revealed significant reciprocal relationships among the variables (see Fig. 2). As predicted by our first hypothesis, there was a significant reciprocal relationship between adolescents' expectations and parents' expectations. More specifically, students' expectations in 8th grade predicted parents' expectations in 12th grade $(b=.17, p<.001)$, and parents' expectations in 8th grade predicted students' expectations in 12th grade ( $b=.21, p<.001)$. Consistent with our second hypothesis, students' expectations and parents' expectations were reciprocally related to academic achievement, such that students' and parents' expectations in 8th grade predicted academic achievement in 12th grade $(b=.07, p<.001$ and $b=.09, \quad p<.001$, respectively), and academic achievement in 8th grade predicted students' and parents' expectations in 12 th grade $(b=.20, p<.001$ and $b=.12$, $p<.001$, respectively).

\section{Gender Differences in the Reciprocal Relationships}

With respect to gender differences, an overall test of model equivalence indicated that some gender differences were present in the model $\left(\Delta \chi^{2}(9)=37.6, p<.001\right)$. The analyses based on multiple-group analyses revealed that males and female were similar with respect to the stability of their expectations and academic achievement from 8th grade to 12 th grade. However, the stability of parents' expectations for males was higher than for females $\left(b=.28, p<.001\right.$ and $b=.23, p<.001 ; \Delta \chi^{2}(1)=12.0$, $p<.001$ ) (see Table 2).

Differences between males and females with respect to the reciprocal relationships among students' expectations, parents' expectations, and academic achievement were minimal, with one interesting exception. Contrary to our third hypothesis, parents' expectations in 8th grade were more strongly associated with students' expectations in 12 th grade among males than among females $(b=.24$, $p<.001$ and $\left.b=.18, p<.001 ; \Delta \chi^{2}(1)=5.4, p<.05\right)$. All other reciprocal relationships did not differ significantly between males and females. 
Fig. 2 Cross-lagged path model representing the reciprocal relationships among students' expectations, parents' expectations and academic achievement. Notes Unstandardized coefficients are reported with standard errors in parentheses. Error term coefficients and correlation coefficients were omitted for presentation purposes

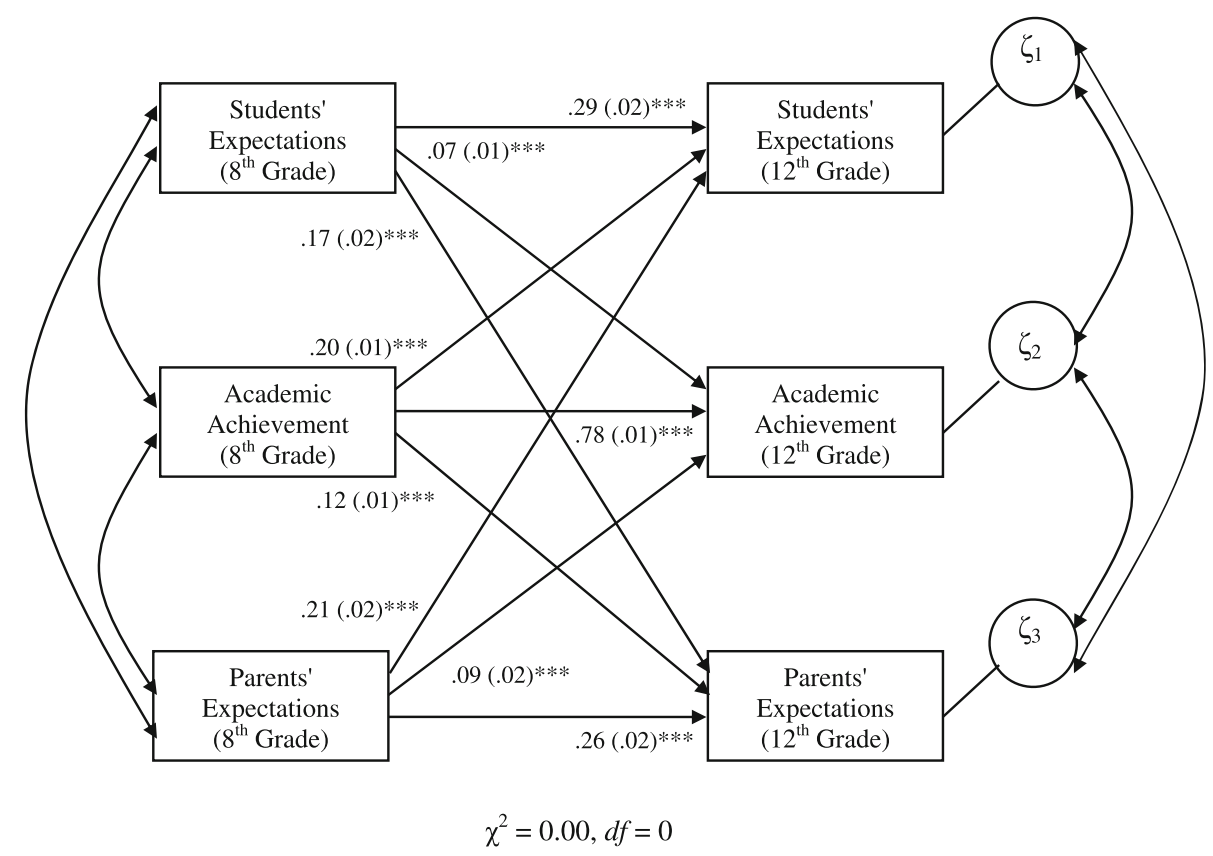

Table 2 Gender differences in the unstandardized coefficients of stability and reciprocal effects of students' expectations, parents' expectations, and academic achievement

\begin{tabular}{|c|c|c|c|}
\hline & $\begin{array}{l}\text { Males } \\
b\end{array}$ & $\begin{array}{l}\text { Females } \\
b\end{array}$ & $\begin{array}{l}\text { Gender differences } \\
\Delta \chi^{2}\end{array}$ \\
\hline \multicolumn{4}{|l|}{ Stability (8th $\rightarrow$ 12th Grade) } \\
\hline Students' expectations $\rightarrow$ students' expectations & $.28 * * *(.02)$ & $.29 * * *(.02)$ & \multirow{3}{*}{$\Delta \chi^{2}(1)=12.0, p<.001$} \\
\hline Parents' expectations $\rightarrow$ parents' expectations & $.28 * * *(.02)$ & $.23 * * *(.02)$ & \\
\hline Academic achievement $\rightarrow$ academic achievement & $.77 * * *(.01)$ & $.79 * * *(.01)$ & \\
\hline \multicolumn{4}{|l|}{ Reciprocal effects (8th $\rightarrow$ 12th Grade) } \\
\hline Students' expectations $\rightarrow$ parents' expectations & $.18 * * *(.02)$ & $.15 * * *(.02)$ & \multirow{6}{*}{$\Delta \chi^{2}(1)=5.4, p<.05$} \\
\hline Parents' expectations $\rightarrow$ students' expectations & $.24 * * *(.02)$ & $.18 * * *(.02)$ & \\
\hline Students' expectations $\rightarrow$ academic achievement & $.09 * * *(.02)$ & $.06 * * *(.02)$ & \\
\hline Academic achievement $\rightarrow$ students' expectations & $.18 * * *(.01)$ & $.20 * * *(.01)$ & \\
\hline Parents' expectations $\rightarrow$ academic achievement & $.09 * * *(.01)$ & $.09 * * *(.01)$ & \\
\hline Academic achievement $\rightarrow$ parents expectations & $.11 * * *(.01)$ & $.11 * * *(.01)$ & \\
\hline
\end{tabular}

Results are based on multiple group analyses in which the overall model (Fig. 1) was initially tested for gender differences $\left(\Delta \chi^{2}(9)=37.6\right.$, $p<.001)$

$* * * p<.001$

\section{Ethnic Differences in the Reciprocal Relationships}

A test of overall model equivalence indicated that ethnic group differences were present in the model $\left(\Delta \chi^{2}\right.$ $(27)=178.0, p<.001)$. Differences in the stability of parents' expectations were detected such that the stability was higher among Whites than Asian, Hispanic, and African Americans $(b=.27, p<.001, b=.18, p<.001$, $b=.16, p<.001$, and $b=.21, p<.001$, respectively; $\left.\Delta \chi^{2}(3)=63.5, p<.001\right)$. The stability of academic achievement also varied by ethnic group such that the academic achievement of African American was more stable than Asian, Hispanic and White students $(b=.86$, $p<.001, b=.80, p<.001, b=.80, p<.001$, and $b=.74, p<.001$, respectively; $\left.\Delta \chi^{2}(3)=49.8, p<.001\right)$ Table 3.

With respect to ethnic differences in the reciprocal relationships among students' expectations, parents' expectations, and academic achievement, three differences emerged. First, academic achievement in 8th grade was more strongly related to students' expectations in 12th grade among White students than among Asian, Hispanic, and African American students $(b=.22, p<.001$, $b=.18, \quad p<.001, \quad b=.20, \quad p<.001$ and $b=.15$, 


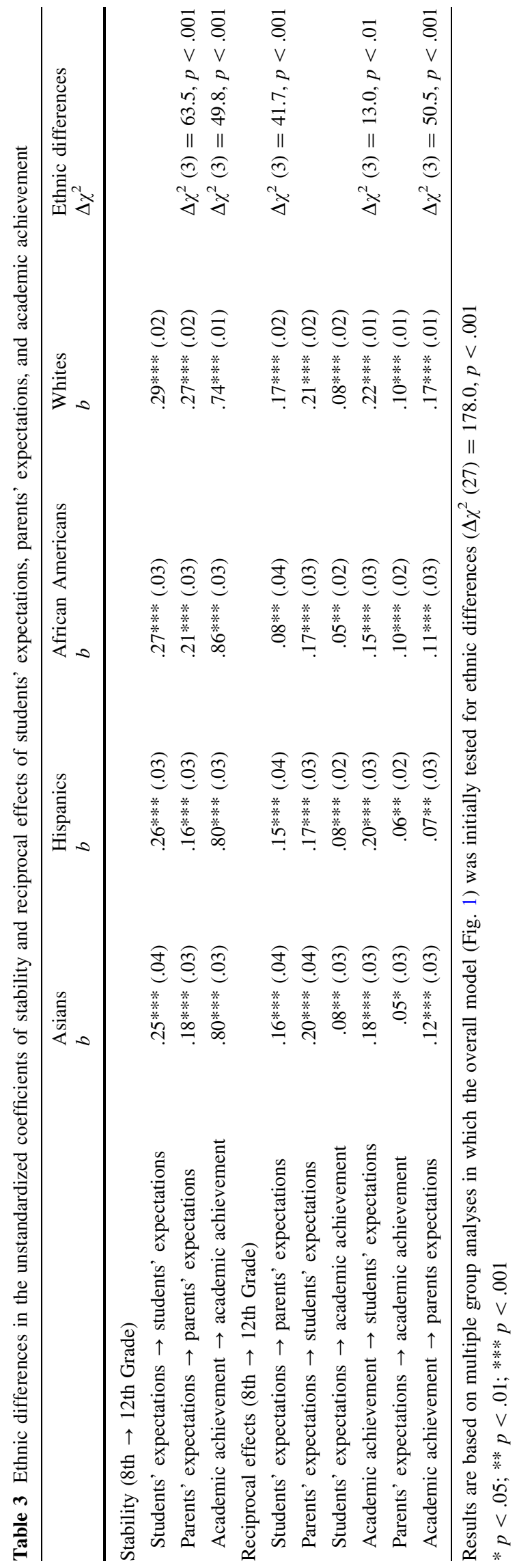

$p<.001$, respectively; $\left.\Delta \chi^{2}(3)=13.0, p<.01\right)$. Second, the same pattern was observed with respect to academic achievement and parents' expectations such that academic achievement in 8th grade was more strongly associated to parents' expectations in 12th grade among White students than among Asian, Hispanic and African American students $(b=.17, p<.001, b=.12, p<.001, b=.07$, $p<.001$ and $b=.11, p<.001$, respectively; $\Delta \chi^{2}$ (3) $=50.5, p<.001)$. It should be noted, however, that the differences in coefficients presented above are small to moderate, with effect sizes ranging from .08 to .25 according to Kline's (1998) guidelines for interpreting the magnitudes of these effects. The third ethnic difference partially supported our fourth hypothesis, which predicted that students' expectations in 8th grade would be more strongly associated with parents' expectations in 12th grade among White students than among other students. Results showed that the relevant coefficient was highest among White students $(b=.17, p<.001)$, but closely followed by Asian and Hispanic students $(b=.16$, $p<.001$ and $b=.15, p<.001$, respectively), all of which were stronger than the coefficient for African Americans $\left(b=.08, p<.001 ; \Delta \chi^{2}(3)=41.7, p<.001\right)$. Also contrary to our fourth hypothesis, we did not find ethnic differences in parents' expectations in 8th grade influencing students' expectations in 12th grade.

To assess whether the reciprocal relationships and their gender and ethnic differences found above could be accounted for by other demographic factors, such as family socioeconomic status and school size, the above analyses were re-run with those demographic factors as covariates. Results showed that the reciprocal relationships and the group differences were robust to the inclusion of various covariates such as socioeconomic status and school size.

\section{Discussion}

A large body of previous research has demonstrated the importance of parental expectations and adolescents' expectations on adolescents' academic achievement. Less is known, however, about the reciprocal relationships among these constructs. The current study examined the reciprocal relationships among parents' expectations, adolescents' expectations, and adolescents' academic achievement, and whether these relationships are moderated by gender and ethnicity. Results demonstrated a reciprocal relationship between parents' expectations and adolescents' expectations, and a reciprocal relationship between expectations (both parents' and adolescents') and adolescents' academic achievement. Furthermore, results indicated that gender and ethnicity moderated these 
reciprocal relationships, such that the effects of parents' expectations on students' expectations were stronger among males than females, and the effects of adolescents' expectations on parents' expectations were weakest among African Americans as compared to other ethnic groups (i.e., Asian, Hispanic, and White Americans).

Our main finding about the formation and effects of parents' expectations was consistent with expectancy-value theory (Wigfield and Eccles 2002), which supports the notion that students' previous achievement affects parents' expectations, which in turn affect students' expectations. More broadly, our results confirm the ecological perspective of factors that affect academic outcomes (Benner and Mistry 2007). Benner and colleagues argue that social determinants with varied level of power and influence (e.g., the individual child, family, and culture, etc.) play a critical role in the process of adolescent development. Consistent with that argument, we found that both adolescents' and their parents' expectations made independent (or unique) contributions to later adolescents' academic achievement. More importantly, our findings extend previous theories, such as the expectancy-value theory, by illustrating that adolescents' expectations also assist in the formation and change of parents' expectations. This finding suggests that, as adolescents grow up, parents become sensitive to their children's goals and wishes. In other words, in adolescence, family socialization becomes dynamic and interactive, rather than what would be supported by the traditional socialization perspective (i.e., parents try to influence their children).

Our second main finding is that these relationships vary by gender and ethnicity. First, although previous studies have shown that the effects of parental expectations on students' expectations are stronger among females than males (Flouri and Hawkes 2008), our results support the contrary. Our finding seems to be consistent with the traditional stereotype that parents place a greater emphasis on their son's education rather than their daughter's education (Lundberg 2005). Researchers argue that the emphasis on sons is due to the parents' optimal response to gender wage differentials rather than unequal concern for sons and daughters (Behrman et al. 1986). It is important to note, however, that the gender difference we found was modest and parents' expectations and adolescents' expectations strongly influence each other, regardless of gender.

The results pertaining to ethnicity suggest that the effects of students' expectations on parents' expectations is weakest among African American students as compared to Asian, Hispanic, and White students. This finding partially supports our fourth hypothesis that predicted that this relationship would be stronger among White students than among other ethnic groups. However, this ethnic difference does not appear to be due to differential values of autonomy. Asian Americans have been reported to have delayed autonomy as compared to Whites (Feldman and Rosenthal 1991), but we found no differences between Asian Americans and Whites. One possible interpretation of our finding is that, compared to other groups, African American adolescents might have been less likely to communicate and convince their parents of the adolescents' own expectations. In support of such a possibility, Toldson et al. (2009) found that African American students, especially those with no plans to attend college, reported less parental involvement as compared to Whites. Another factor is that more African American adolescents do not have access to their father as compared to other groups. Consequently, more African Americans than Whites regarded teachers as important in helping them make educational decisions (Mahoney and Merritt 1993). Based on this discussion, it appears that future research should further examine ethnic differences in all sources of social support for adolescents' educational decision making.

Although we expected that the effects of parents' expectations on students' expectations would be strongest among Asian Americans, we did not find ethnic differences in such effects. Previous literature documented that Asian adolescents' expectations are more strongly influenced by their parents' expectations than other ethnic groups (Chen and Lan 1998; Goyette and Xie 1999), our findings, however, suggest that parents' expectations have a strong influence on students' expectations, regardless of ethnicity. We further found that academic achievement among White students is more strongly associated with students' expectations and parents' expectations than among Asian, Hispanic and African American students. White students appear to recalibrate their educational aspirations according to their achievement, whereas the latter three groups appeared to hold onto their original aspirations regardless of their level of achievement. This finding is in general consistent with the long-standing result that African and Hispanic Americans hold high expectations regardless of the educational inequality in reality (Chang et al. 2006). However, caution should be taken in interpreting these results given that the magnitude of these effects is quite small. Additional analyses are necessary to elucidate these findings.

The current study has several important limitations that should be noted. First, the NELS data are somewhat dated, with adolescents in the study now being well into adulthood. Although certain processes such as parent-adolescent relationships may not have changed dramatically, other contexts likely have changed. Of particular relevance to this study, gender differences in educational attainment have likely diminished over the last two decades. Such changes would limit the generalizability of findings from 
this dataset to the current population. Second, although five waves of data are available in the NELS dataset, only two waves include parental reports of expectations, resulting in our analyses being limited to these two waves of data. Moreover, because the two waves used in the study span 4 years, only long-lasting effects were able to be detected in our study. This relatively large gap between waves may have made our estimates of the effects (e.g. the reciprocal relationships) rather conservative. A third limitation of this study is the limited scope of variables included in the study. It is likely that psychological moderators, such as student self-esteem and locus of control, are related to the constructs examined in the present study, however they are beyond the scope of the current study in which the primary goal was to establish the reciprocal relationships model. Future research would benefit from replication of the findings from a more current sample, more waves of longitudinal data, and more variables tapping social contexts (parents, teachers, and friends).

The findings from this study highlight the often overlooked complexity in the relationships among parents' expectations, students' expectations, and academic achievement. Specifically, not only do parents' expectations influence students' expectations, but students' own expectations can also influence parents' expectations, both of which independently influence and are influenced by students' achievement. Furthermore, these relationships are sometimes moderated by gender and ethnicity. Such findings have important implications for policy makers aiming to improve the academic achievement of adolescents by raising academic expectations of both parents and students.

Open Access This article is distributed under the terms of the Creative Commons Attribution Noncommercial License which permits any noncommercial use, distribution, and reproduction in any medium, provided the original author(s) and source are credited.

\section{References}

Aldous, J. (2006). Family, ethnicity, and immigrant youths' educational achievements. Journal of Family Issues, 27, 1633-1667.

Bandura, A., Barbaranelli, C., Caprara, G. V., \& Pastorelli, C. (1996). Multifaceted impact of self-efficacy beliefs on academic functioning. Child Development, 67, 1206-1222.

Behrman, J. R., Pollak, R. A., \& Taubman, P. (1986). Do parents favor boys? International Economic Review, 27(1), 33-54.

Benner, A. D., \& Mistry, R. S. (2007). Congruence of mother and teacher educational expectations and low-income youth's academic competence. Journal of Educational Psychology, 99, $140-153$.

Chang, E., Chen, C., Greenberger, E., Dooley, D., \& Heckhausen, J. (2006). What do they want in life? The life goals of a multiethnic, multi-generational sample of high school seniors. Journal of Youth and Adolescence, 35, 321-332.

Chen, H., \& Lan, W. (1998). Adolescents' perceptions of their parents' academic expectations: Comparison of American,
Chinese-American, and Chinese high school students. Adolescence, 33, 385-390.

Curtin, T. R., Ingles, S. J., Wu, S., \& Heuer, R. (2002). User's manual: Base-year to fourth follow-up: Student component data file (NCES 2002-323). Washington, DC: U.S. Department of Education.

Eccles, J. S., \& Wigfield, A. (2002). Motivational beliefs, values, and goals. Annual Review of Psychology, 53, 109-132.

Ensminger, M., \& Slusarick, A. (1992). Paths to high school graduation or dropout: A longitudinal study of a first grade cohort. Sociology of Education, 65, 95-113.

Feldman, S. S., \& Rosenthal, D. A. (1990). The acculturation of autonomy expectations in Chinese high schoolers residing in two western nations: Effects of length of residence. International Journal of Psychology, 25, 259-281.

Feldman, S. S., \& Rosenthal, D. A. (1991). Age expectations of behavioral autonomy in Hong Kong, Australian and American youths: The influence of family variables and adolescent values. International Journal Psychology, 26, 1-23.

Feldman, S. S., Rosenthal, D. A., Brown, N., \& Canning, R. (1995). Pathways to early sexual intercourse: A longitudinal study of the influence of peer status. Journal of Research on Adolescence, 5, $387-412$.

Flouri, E., \& Hawkes, D. (2008). Ambitious-mothers-successful daughters: Mothers' early expectations for children's education and children's earnings and sense of control in adult life. British Journal of Educational Psychology, 78, 411-433.

Garg, R., Kauppi, C., Lewko, J., \& Urajnik, D. (2002). A structural model of educational aspirations. Journal of Career Development, 29, 87-108.

Goldenberg, C. N., Gallimore, R., Reese, L. J., \& Garnier, H. (2001). Cause or effect? A longitudinal study of immigrant Latinos' parents aspirations and expectations and their children's school performance. American Educational Research Journal, 38(3), $547-582$.

Goyette, K., \& Xie, Y. (1999). Educational expectations of Asian American youths: Determinants and ethnic differences. Sociology of Education, 72, 22-36.

Halpern, D. F. (2000). Sex differences and cognitive abilities. Mahwah, NJ: Erlbaum.

Hao, L., \& Bonstead-Bruns, M. (1998). Parent-child differences in educational expectations and the academic achievement of immigrant and native students. Sociology of Education, 71, 175-198.

Ingels, S. J., \& Quinn, P. (1996). Sample exclusion in NELS:88. Characteristics of base year ineligible students: Changes in eligibility after four years. Technical Report (NCES 96-723) Washington, D.C.: U.S. Department of Education, National Center for Educational Statistics.

Ingels, S. J., Scott, L. A., Lindmark, J. T., Frankel, M. R., \& Meyers, S. L. (1992). National education longitudinal study of 1988: Data file user's manual. Washington DC: U.S. Department of Education, Office of Educational Research and Improvement. NCES 92-085.

Ingels, S. J., Scott, L. A., Taylor, J. R., Owings, J., \& Quinn, P. (1998). National education longitudinal study of 1988 (NELS:88) baseyear through second follow-up: Final methodology report. Washington, DC: National Center for Education Statistics.

Kao, G., \& Tienda, M. (1998). Educational aspirations of minority youth. American Journal of Education, 106, 349-384.

Kline, R. B. (1998). Principles and practices of structural equation modeling. New York: Guilford.

Lundberg, S. (2005). Son, daughters and parental behavior. Oxford Review of Economic Policy, 21(3), 340-356.

Mahoney, J. S., \& Merritt, S. R. (1993). Educational hope of black and white high school seniors in Virginia. Journal of Educational Research, 87(1), 31. 
Mau, W. C., \& Bikos, L. H. (2000). Educational and vocational aspirations of minority and female students: A longitudinal study. Journal of Counseling \& Development, 78(2), 186-195.

Mello, Z. R. (2008). Gender variation in developmental trajectories of educational and occupational expectations and attainment from adolescence to adulthood. Developmental Psychology, 44, 1069-1080.

Mello, Z. R., \& Swanson, D. P. (2007). Gender differences in African American adolescents' personal, educational, and occupational expectations and perceptions of neighborhood quality. Journal of Black Psychology, 33, 150-168.

Mistry, R. S., White, E., Benner, A. D., \& Huynh, V. (2009). A longitudinal study of the simultaneous influence of mothers' and teachers' educational expectations on low-income youth's academic achievement. Journal of Youth and Adolescence, 38, 826-838.

Morgan, S. L. (1996). Trends in black-white differences in educational expectations: 1980-1992. Sociology of Education, 69, 308-319.

Muthén, B., \& Satorra, A. (1995). Complex sample data in structural equation modeling. In P. V. Marsden (Ed.), Sociological methodology (pp. 267-316). Washington, DC: American Sociological Association.

National Center for Educational Statistics (NCES). (2005a). Trends in average mathematics scale scores by racelethnicity: White-Black gap. Retrieved from http://nationsreportcard.gov/ltt_2008/ ltt0005.asp?tab_id=tab2\&subtab_id=Tab_1\#chart.

National Center for Educational Statistics (NCES). (2005b). Trends in average mathematics scale scores by race-ethnicity: WhiteHispanic gap. Retrieved from http://nationsreportcard.gov/ 1tt_2008/ltt0005.asp?tab_id=tab3\&subtab_id=Tab_1\#chart.

Patrikakou, E. N. (1997). A model of parental attitudes and the academic achievement of adolescents. Journal of Research and Development in Education, 31, 7-26.

Patton, J. M. \& Royer, J. M. (2009). The influence of gender and ethnicity on numeracy acquisition. Encyclopedia of language and literacy development (pp. 1-7). London, ON: Canadian Language and Literacy Research Network. Retrieved from http:// www.literacyencyclopedia.ca/pdfs/topic.php?topId=268.

Rosen, B. C., \& Aneshensel, C. S. (1978). Sex differences in the educational-occupational expectation process. Social Forces, 57, 164-186.

Smith, T. E. (1981). Adolescent agreement with perceived maternal and paternal educational goals. Journal of Marriage and the Family, 43, 85-93.

Smith, T. E. (1991). Agreement of adolescent educational expectations with perceived maternal and paternal educational goals. Youth \& Society, 23, 155-174.
Sue, S., \& Okazaki, S. (1990). Asian-American educational experience. American Psychologist, 45(8), 913-920.

Toldson, I. A., Braithwaite, R. L., \& Rentie, R. J. (2009). Promoting college aspirations among school-age Black American males. In H. T. Frierson (Ed.), Black American males in higher education: Research, programs and academe diversity in higher education (pp. 117-137). UK: Emerald Group Publishing Limited.

Trusty, J. (1998). Family influences on the educational expectations of late adolescents. Journal of Educational Research, 91, 260-270.

Wigfield, A., \& Eccles, J. S. (2002). The development of competence beliefs, expectancies for success, and achievement values from childhood through adolescence. In G. Phye (Ed.), Development of achievement motivation (pp. 91-120). San Diego: Academic Press.

\section{Author Biographies}

Yanyan Zhang M.A. received her Master Degree in Social Psychology in China. She is currently a Ph.D. candidate in the Department of Psychology and Social Behavior at University of California, Irvine. She is interested in cross-cultural studies of academic achievement; evolution and mate selections; moral reasoning and punishment of transgressions.

Eileen Haddad is a doctoral student in the Department of Psychology and Social Behavior, University of California-Irvine. Her current research interests include social influences on adolescent and young adult development.

Bernadeth Torres M.A. was a former doctoral student in the Department of Psychology and Social Behavior at University of California, Irvine. Her area of interest was late adolescence, in particular, ethnic differences in the transition from high school to college and in academic achievement.

Chuansheng Chen Ph.D. is a professor in the Department of Psychology and Social Behavior at University of California, Irvine. $\mathrm{He}$ is interested in culture, ethnicity, and adolescent development; the role of non-parental adults in adolescent development; brain imaging of language and mathematical learning; culture and creativity; methodological issues in cross-cultural research; evolution, genes, and behavior. 